\title{
Reading Classical Authors in the Digital Era
}

Vehbi Miftari

Arbnore Mahaj

\begin{abstract}
Statement of the problem: Learning about classic authors, whose language is hardly understandable for children, has become a challenge. The decline of literary reading and the lack of focus in the subject matter and idea of the text, which are interrelated to the early culture / identity, make students lose their will to read classic works, thus failing to fulfil the aims and competencies required with the Pre-university Curriculum Framework. Methodology: The research is based on the analysis of Curriculum Framework and the structure of school subjects. Furthermore, methods of teaching classic works and use of complementary means are treated through a combination of quantitative method with the ethnographic one. Results: The research concludes that students tend to read classic works (works by old authors) more easily if they are offered the abridged versions. Making of abridged collections of such works, and complementing book contents with digital content is the tendency that schools have in the digital era. Conclusions / recommendations: MEST should aim towards changing the structure of language and literature course, draft new programs, and prepare additional content for teaching and learning of texts and classic authors (e-school).
\end{abstract}

Keywords: classic authors, curriculum aims/competencies, school texts, abridged versions, digital content.

\section{Introduction}

Reading the classics can awaken "the echo of bygone times in the story." British Library has transformed this echo in a transcendental echo of reading: new books are stretched with contents of the earlier books. This echo is comparable with those of two great classic authors: Jorge Luis Borges and Italo Calvino. Borges did mention the transcendental echo of the earlier works in his theory of twelve metaphors known widely. Italo Calvino, on the other hand, offered fourteen reasons why we should permanently read the classics of literature.

Considering classic authors, nowadays we find the echo of the past times in their works coming back in such form that we continuously discover ourselves in a narrative overview. That's why we see the classic texts as a permanent source on which even the curricular aim of cultivating the cultural and national identity is based.

Literature as bearer of cultural memory builds an inseparable part of our cognitive universe and plays a role in highlighting the transformation of our everyday experiences in aesthetic experience (Sanz \&Romero, 2007: 6). But, the reading of classic authors, whose language is hardly understandable for children, has become a school challenge. The decline in reading and focusing in the subject and text ideas, which are related to the early culture / identity affects the students will to read classic works and, consequently, they do not meet at least one of the goals of the Curriculum Framework of Preuniversity Education, especially the first goal (article 1.3.): cultivation of personal identity, national and cultural background of the state, and its first competency, that is achieving communication and expression skills.

In the other hand, the barriers that children have in adapting their language competencies (Eco, 2000: 13) and their encyclopaedic competency, can have an immerse impact in the relations the students will create with the classic texts and authors. 
Hence, the teaching methods should consider the clash between those competencies of the reader and the curricular goals and competences. As far as the national education system does not provide any particular program (which would be part of a course program offered by teachers, and which would consist in improving teacher's competencies and the ways they align the readers competencies with those curricular competencies), students will refuse to focus in the subject and ideas of the texts which are related to the early culture / identity and will diminish students' will to read classic works and, consequently, they do not meet at least one of the goals of the National Curriculum.

\section{Why Read the Classics?}

This paper presents an effort to align the curricular competencies with reader's competences and teacher's skills in offering the content to the students, even though they do not have a systematic program to evaluate students' progress. This form of evaluation would represent an effective mechanism in proving whether the goals and objectives written in the National Curriculum have influenced the learning behaviours of students in the learning process or whether a school has been successful in creating a positive learning environment, in which the reading of the classic authors would be easily possible.

We will also analyse the traditional course structure, considering the difficulties in absorption of the course content and the materials teachers are using to offer the classic text to students.

As a logical step, at the last part, the texts will be analysed within the new proposed structure of the course and an additional mechanism will be offered in creating a better learning environment, in which students, using some new digital tools and digital content will be approximated to a learning environment in which their competencies (including encyclopaedic, language and extra textual competencies) will be closer to the course structure and its content.

\section{Curricular Competencies / Reading Competencies}

The curriculum competencies imply that teachers have a duty to help students achieve some basic competencies. As mentioned, the cultivation of the personal, national and state identity as well as cultural background are the main goals. Therefore, the Albanian Literature and Language course structure should be adapted to this goal and provide the result: the improvement of the communication skills and expression. For this aim/competency, in the course structure, the curriculum offers some basic classic authors like: Marin Barleti, Gjon Buzuku, Pjeter Budi, Pjeter Bogdani etc. They have a central role in the content of school textbooks. Through their texts the curriculum has foreseen the fulfilment of these goals / competencies. But the manner of delivery of texts, as far as their language, are often incompatible with the students' competencies and their orientation towards new technologies.

The classical debate on the level of cooperation of readers with the text consists mainly between the text as a code structure (theory of the codes) and the encyclopaedic competency of the reader (Eco, 2000, 13). How to offer the book content to the students' using a language that is suitable to their level of knowledge, their lexical and language competency and their possibility to create an approach to the text?

The inter-connective structure of the texts, at its ideal level, should provide such a discursive opportunity that it would help readers use their language and extra language competency to understand the text and to be able to learn from it. The role of the curriculum framework should consist on offering a specific course program, learning materials and tools which create a close contextual competency, suitable for both the author (the strategy of the author) and the reader (the strategy of the text). Therefore, the contextual selection is important to all: curriculum experts, course program writers and learning strategists. They should all have an approach which produces a learning platform in which all parties are text-oriented. The competency of the text (offered by the text), adaptable with that of the reader, being used in this learning platform, would help the creation of the third level of the competency: the text competency $(E c 0,2000)$, which will be used in an effective learning environment. Creating a comfortable learning environment, like a reading chair or author's hat in the classrooms promotes the Love of Reading (RICA, 2007: 23) and improves students' learning behaviours.

The ability to read the classic texts, written in a dialect or even more in one of the idiolects, is one of the crucial tests of the today's technology oriented society. Even though the instructional reading is considered to be between 92-97 percent of accuracy level (Tabersky), there are different text oriented approaches which help students to create a reading skills and competencies. The most known are: the method which emphasizes the meaning and the second which emphasizes the decoding (Schwartz, 1984: 12). Undependably, if students are focused in "sounds and words "or look and say" method, the reading skills they will get depend on the materials that we offer them. Therefore, taking into consideration the different 
cultures and experiences of students, we should offer to them specific materials which would be acceptable by them in teaching process and would help them to achieve the reading competences. That would help them create a positive approach to the classic authors as well. Therefore, getting good reading skills is a key to getting good learning skills. The children who do not learn to read well will not easily master other skills and knowledge (Wynne, 2008: X). The challenge will become even higher if we analyze the reading skills of children to read the classic authors and books. Children whose language and extra textual competencies are not in accordance with the text content and text language will not be able to develop enough skills and get knowledge. As a result, they will not fully achieve the curricular competencies, like the communication and expression for their personal, cultural or national identity. For this purpose, RYCA has proposed to conduct the assessment of the reading development of the students, as a reflective process of the students. The understanding of the classic texts, as an assessment process as a whole is very complex, but it must include one very important question, made by the students themselves: "Do I understand what the author was going to say"? (Wynne, 2008: 15). Will the students really be able to understand the so called intentio auctoris (Eco, 1995: 35) if they did not develop good reading skills and have a lack of knowledge and competencies?! And, how does the Curriculum Framework stimulate the achievemen of those reading competencies by the children? As we have explained in the paper: The Impact of the Curriculum Framework in the Literary Writing of the Children in Lower Secondary School ${ }^{1}$, the Curriculum competencies are gained mainly through: a) listening and speaking; b) reading and c) writing. The curriculum does not, however, specify two very important tools in achieving the communication skills, the questioning and discussing (Musai, 225). The questioning, in itself, helps schools in planning, organizing and managing the reading instructions and, through them, mastering more skills and competencies. On the other hand, discussing or using oral language activities can be an effective tool for promoting the reading comprehension or the critical meaning by the children.

However, the development of the phonological and linguistic approaches is crucial in preparing students to work with classic authors. The language competency remains a crucial factor in creating a positive environment for mastering reading skills. In order to benefit from the activity with the classic texts, students must have a certain level of linguistic awareness, including phonemic and lexical awareness. Only at the level in which the students have achieved a good level of language competency we can consider that they will be able to work with the strategy of the text, through the fifth reading competency: the word identification strategies, which provide the transformation of communication signals into messages throughout the decoding process (Wynne, 2008: 55). This transforming process brings the students in a platform where they are able to use the literary response to the texts and analyses. They will be ready to develop the literary analyses skills, which means: the analyses of the story elements, the character development, figurative language, literary allusions, the author's point of view and genre. This process will be of a high benefit for the students. They will not only get the skills and knowledge, or develop an independent reading process, but they will also develop further the oral and written language skills and achieve a satisfactory level of a vocabulary development. In adittion, students will reach to a certain personal or cultural level which allows a good communication and expression and stimulate the awareness on the personal and cultural identity, which, as mentioned above, is one of the priority competencies.

\section{Course Structure / Reading Competencies}

The practical problem is that the course program and its tools are often not adaptable with the aim. The reader competencies are not in accordance with the text structure and text language. Therefore, the evaluation of the traditional course structure with the aim to identify the tools and materials to be used in a new course structure would be helpful for implementing this theory: the relation between curriculum, text and teaching strategy.

Consequently, schools are struggling between the traditional concept of learning delivery, , and the modern one, which means reforming the existing curriculum and the inclusion of digital content and digital media in the transmission of knowledge to students..

These two incompatible concepts affect the learning environment and individual learning behaviour because the students' habits are different: some learn textbook content very easily if it is accompanied with visualization; others, however,

\footnotetext{
1 The Impact of the National Curricula in the imaginative work of the studentes of the primary schools; Lublin, Poland, 17-19 May 2017, The Mamagment, Knowledge and Learning International Conference 2017; organized by: International School for Social and Business Studies (ISSBS), Slovenia; Maria Curie-Sklodovska University, Poland and Kasetsart University, Thailand;
} 
understand more deeply if the content is provided in writing. For the first group it is necessary to use additional materials and tools to facilitate the transfer of knowledge.

But, there is an another issue, which is sensitive to both categories: communication texts and classic authors, whose language is "archaic", written in dialect or even idiolect, which may or may not coincide with the language "used" by students. Children are usually more focused on the meaning than in the words (Taberski). The problem is that the text often does not provide language adaptable with their competencies, so they lose the meaning having not understood the words. The glossary helps them to identify the meanings of the word before they understand the meaning of the text.

\section{1. The traditional course structure}

Based on the Curriculum Framework of Pre-University Education, the structure of language and literature course has set several goals, achievable through the provision of works / literary texts of the authors varying from the Middle Ages onwards. These targets consist primarily in knowledge acquisition, language training, cultural training, and formation as an individual and as a citizen. As goals related directly to lower secondary school, they will highlight the mastery of the native language and literature, and recognition of the culture. The basic tools for achieving this goal are the most popular literary works, including those of the classic authors. The aim is to offer students the opportunity to get good language skills, structured thinking and independent judgment, in addition to expanding their imaginative space.

At this point, communication with literary texts becomes crucial to meet these goals. But, texts contained in the curriculum are different, written at different times and with relatively different language.. The texts of contemporary authors can be understood more easily, since the language used in them is closer to students' linguistic and encyclopaedic competences.

Therefore, curriculum and course program have provided uniform method of text reading, and common goals which should be obtained as a result of communication with these texts. But, uniform communication and the same interactive methodology of teaching cannot be uniform as to archaic language of Buzuku, or to the northern Albanian Language idiolect of Fishta. The decoding process will be very difficult and different from each-other. But, once realized, this decoding process will not imply the reading comprehension, even though it has been considered for a long time that the successful decoding results in reading comprehension (Fries, 1962). Consequently, it will be quite difficult to get the comprehension skills from the reading process of classic texts if the decoding process would not be supported by asking inferential and critical thinking questions which would challenge and engage the students in the text (RICA, 2008: 13). Not questioning means depriving students of the possibility of extracting the meaning of the text, which based on the bottom-up theory should begin with the smallest parts, often phonetic ones, and continue to the general meaning of the text. Likewise, the children will not be equipped with the necessary language skills and will not be able to expand their judgmental skills. By not communicating with these texts, students will not achieve the course objectives. Not knowing basic forms and discourses of textbooks, readers cannot develop basic communication skills as a required curriculum competency, will not be able to cultivate a sense of togetherness and cultivate cultural and national identity.

\subsection{Modern course structure}

Nowadays, schools are struggling between the traditional concept of learning delivery, on one hand and modern style, which means reforming the existing curriculum and the inclusion of digital content and digital tools in transmission of knowledge to students, on the other hand. The involvement of the 'open online courses' (MOOC's) submits the vision for the next digital school. The contemporary structure of the Albanian Language and Literature course, therefore, must rely on the provision of printed textbooks as basic tools for providing knowledge, but in versions suitable for children, as well as providing additional digital tools. Supporting materials are needed for easy comprehension of the authors of literary texts, especially the classic authors.

As stated here, we note that the idea to read the classics offering students only printed publications ignores technological expectations (i.e. the use of e-publications) and does not meet curricular goals. These auxiliary materials do not "revolutionize" school, a conservative institution that supports the hard changes, nor digitize it, as a result of the use of technology in providing additional knowledge. After all, auxiliary materials have been ever-present in of the reading of texts in our past: a glossary, an illustrated book, a page or a printed booklet notes. They create a hypertext based on the content of the courses offered in the curriculum. This has already happened to most of the arts, in which technology, new media, 
are increasingly present in the way of transmission / knowledge learning. Literature seems to have remained the only one of the arts which still resists the use of technology in providing knowledge seems. Even for its teaching, additional content which would accompany the basic content of the course is rarely used in schools.

\subsubsection{Abridged versions}

How can children read the works of classic authors like Barleti or Fishta? Are they prepared to read these works if that is a hardly accessible world, expressed with archaic language? Providing auxiliary materials, such as abridged collections, blogs, dramatic story, games etc., as well as video interviews with different actors or writers, may align these works with students.

Offering abridged versions (shortened versions of books) becomes necessary especially for understanding the content of texts and authors, whose work is hardly understandable. Today it is difficult to find students who have the patience to read "Missal" of Buzuku transliterated into Latin, and even less in its Albanian version.

\subsubsection{Digital content}

Having mentioned all of the above, the provision of additional materials becomes an immediate need. Through new media, classics of literature can be offered to children in a technologic version, accessible to their imagination and helpful to them in acquiring communication skills. Today the Skanderbeg History is not offered to students only in a book format. Besides that, teachers recommend students to watch the movie together, so that they can discuss about it. As a text that reminds them the great history, it can be read by students if it is provided in a language comprehensible to them, accompanied with additional material, throughout which they would be able "to learn, for example, where the famous castle of Sfetigrad can be found today, or to understand how the formations of the army prepared for battle looked like.

\subsubsection{Author-specific websites}

One of the ways technology can be used to learn the authors' works are the author-specific websites. These sites offer students an opportunity to improve reading and writing skills, using the possibility to learn through modern authors. But, the case is different with the classic authors. In this case, the website should be oriented in knowing the discourses, using the texts and, perhaps, discuss with the writers or literary critics about the ideas, themes and discourses of the classic author.

\section{Conclusions}

Analysis of the curricula that provide teaching methods of classic works through the development of shortened versions (abridged versions), as well as digital content, digital media (digital tools), blogs and online gaming seems to be the future of the structure of the Albanian Language and Literature course. Ministry of Education, Science and Technology (MEST) should develop programs and projects to include supporting materials for teaching texts and classic authors (e-schools), as well as provide materials for teachers, which would facilitate communication and presentation of these texts. Today, the Curriculum Framework does not specify the methodology of acquiring communication skills as a result of their use. It is necessary to design a new contemporary structure of the course, including the teaching materials. Schools should increase the capacities to use auxiliary materials for teaching works of classic authors.

The "School Me" education program has already provided additional tools for teaching different subjects in schools teaching in Albanian language, from first grade to ninth grade. Through it, students gain the knowledge audio visually. This content can additionally transform not only the methodology of teaching, but can also provide an easier understanding of forms, discourses and ideas of the text (broadcast audio visually), although its content is not yet adapted to the curriculum of lower 
secondary school grades. It incorporates the rules of spelling and other language lessons, but lessons for Albanian literature are still not part of the program.

\section{Reference List:}

[1] Anders, P., \& Boss, C. (1986). Semantic feature analysis: An interactive strategy

[2] for vocabulary development and reading comprehension, Journal of Reading, 29, 610-616;

[3] Eco, Umberto. (2000) Testo e enciclopedia, in: Lector in fabula, Tascabili Bompiani, Milan, Italy: 15-26;

[4] Eco, Umberto. (1995), Interpretazione e sovrainterpretazione, RCS Libri, Milano, Italy;

[5] Ilnuma Mizuho, (2016), Learning and Teaching with Technology in the Knowledge Society - New Literacy, Collaboration and Digital Content, Springer, US;

[6] Literature in the Digital Era, edited by: Amelia Sanz and Dolores Romero ("Cambridge Scholars Publishing", New Castle, UK, 2007);

[7] Stefan Schwartz, Measuring Reading Competence - A Theoretical Prescriptive Approach (1984), Springer Sciences and Bussines Media, Plenum Press, New York, US;

[8] Sharon Wynne. (2008) Reading Instruction Competence Assessment (RICA) - Teacher Certification Exam, XAMonline Inc., Boston, US; 